\title{
O MOVIMENTO FEMINISTA BRASILEIRO COMO AGENTE NA CONQUISTA DOS DIREITOS HUMANOS DAS MULHERES
}

\section{THE BRAZILIAN FEMINIST MOVEMENT AS AN AGENT IN THE CONQUEST OF WOMEN'S HUMAN RIGHTS}

\author{
Gabriela Aguiar Palhano ${ }^{1}$ \\ Neide Célia Ferreira Barros ${ }^{2}$
}

\begin{abstract}
Resumo: O presente trabalho tem por objetivo apresentar um breve histórico do movimento feminista em sua variedade e salientar como os embates e as ideias destas organizações fomentaram o desenvolvimento dos Direitos Humanos para um grupo específico. Tratará ainda do histórico precedente da Lei 11.340/06 e de como esta trouxe mecanismos para coibir a violência doméstica intrafamiliar e como esta reflete na conquista de dignidade das mulheres.
\end{abstract}

Palavras-Chaves: História, Direitos Humanos, Feminismo.

\begin{abstract}
The present article has the objective to present a brief historic about feminism and its variety and yet emphasize how the disagreements and the ideas those organization stimulated the human rights development for a specific group. Beyond this topic, this article will bring the history about the 11.34006 law - and how this legislation brought tools to restrain the familiar and domestic violence - and will explain the outspread those rules in the conquest of the women`s dignity .
\end{abstract}

Keywords: History, Human Rights, Feminism.

A historiadora Lynn Hunt (2009) em seu celebrado livro "a invenção dos Direitos Humanos" fala no terceiro capítulo sobre as primeiras formulações que pensaram em garantias sociais e ideias de igualdade institucionalizadas em leis e destaca as declarações dos Estados Unidos, Grã-Bretanha e França como os grandes exemplos e precursores dos Direitos Humanos contemporâneos.

Destes textos mencionados, se olharmos para o modelo francês escrito no calor da revolução, que foi chamado de "Declaração Universal dos Direitos do Homem e do Cidadão (1789)" veremos a ideia de homem universal, homem como sinônimo de humano. Em contraponto a esta compreensão a contemporânea dos autores da declaração e companheira da revolução Marie de Gouzes, conhecida pelo pseudônimo de Olympe de Gouges, entendeu que uma declaração que tratava apenas do homem e do masculino como universal não era suficiente para atender as necessidades do seu sexo, e assim criou a "Declaração dos Direitos da Mulher e da Cidadã" em 1791, que apesar de apresentada em Assembleia não entrou na pauta revolucionária (SILVA \& NUNES, 2016, online).

Dois anos depois Gouges foi guilhotinada no período que ficou conhecido como terror jacobino, por ser considerada por Robespierre e seus companheiros uma mulher perigosa à revolução. Apesar dos dezessete artigos escritos por Olympe de Gouges nunca ter entrado em vigor, o seu manifesto denotou a insatisfação feminina diante da ideia de masculino universal e que era necessário olhar para especificidade feminina para se alcançar a famigerada igualdade tão cara neste momento de profunda transformação do mundo ocidental. Para ela, dar direitos iguais ao homem não era suficiente para criar uma sociedade verdadeiramente igualitária.

Pois como mesmo lembra Joan Scott no período 
da Revolução Francesa "diferenças de nascimento, de posição, de status social entre homens não eram levadas em consideração (...); diferenças de riqueza, cor e gênero sim” (2005, p.15)

Somente um século depois, com a luta de organizações femininas, que as mulheres passaram acessar direitos já garantidos aos homens pelas revoluções da burguesia. Deste modo se Hunt acredita que tais revoluções foram os "grandes exemplos" para os Direitos Humanos, ainda que concordemos com o enorme avanço alcançado por estas, entendemos também que o feminismo foi a alavanca para a igualdade feminina e consequentemente os direitos humanos para mulheres.

Neste trabalho olharemos como este movimento, possibilitou o alcance dos Direitos Humanos para mulheres, especialmente na questão de medidas pelo fim da violência de gênero. Lançaremos a visão para os avanços no território nacional com a apresentação do histórico e peculiaridades na aplicação da Lei n. 11.340/06 (Lei Maria da Penha - LMP) e seus desdobramentos.

\section{Breve história do Movimento Feminista no Brasil:}

Ao longo da história há inúmeros relatos de resistências feminina e insurgência contra um regime patriarcal. Da imagem de Lisístrata na Grécia Antiga à François Poulain de la Barre na França absolutista muitas mulheres se rebelaram em suas limitações de gênero. Porém levando em conta a fala de Lucien Febvre que diz que o anacronismo é o maior pecado que um historiador pode vir a cometer, ignoraremos as falas que remetem o feminismo a tais resistências ao longo da história, e buscando nos livrar da danação no julgamento de Clio, entenderemos neste texto como feminismo somente os movimentos a partir de organizações de mulheres após a segunda metade do século XIX.

Maria Luiza Gonçalves de Abreu diz que o termo feminismo começa a ser usado em língua portuguesa a partir do começo do século XX, e foi oficialmente considerado um verbete no Novo Diccionario da Lingua Portuguesa, de Candido Figueiredo, publicado em Portugal em 1913. Para esta autora, no Brasil o uso contínuo do termo passou a ser usado a partir dos anos 1920. E que antes de ser implementada na língua lusitana, tal terminologia teve sua origem no francês e foi traduzida para a língua inglesa, onde artigos e textos ganharam difusão ao redor do mundo. Todavia especificar a origem exata do termo ainda é um pouco controverso. Diz:

A invenção do termo "feminismo" é recorrentemente atribuída a Charles Fourier, que o teria utilizado em sua obra Quatre mowvements, publicada pela primeira vez em 1808. Mas segundo Karen Offen (2000), Fourier não utiliza o termo. De qualquer modo, a origem da palavra permanece controversa. A primeira menção ao termo "feminista" é menos problemática. Alexandre Dumas Filho o utiliza em 1872 em sua obra L'Homme- femme. HubertineAuclert (1848-1914), defensora do direito ao sufrágio feminino, proclama-se publicamente "feminista" em 1882. No entanto, segundo Offen, ambos os termos entraram de fato no discurso público francês somente na última década do século. A partir de 1892 "feminisme" e "feministe" passariam a ter uso corrente em francês (França, Suíça e Bélgica). O termo rapidamente se difunde para outros países. (2015, online) 
No Brasil, o feminismo surgiu em um contexto de profundas mudanças sociais, no início do século XX. Tais transformações muito motivadas pela expansão capitalista que estendia sua influência a partir da Europa para o resto do mundo, na segunda metade do século XIX. Os primeiros anos da República, proclamada em 1889, abriu espaço para as novidades da chamada modernidade. Nesta esteira padrões sociais foram reformulados num processo de urbanização e industrialização especialmente na região sudeste do Brasil. Neste contexto surgiu as primeiras organizações femininas, que posteriormente se auto nomeariam feminista, buscando direitos políticos. (SEVCENKO, 1998, p.7-48)

Neste período se destacou a Revista Feminina, que circulou no Brasil entre 1914 e 1936, e dentre suas contribuições se posicionaram contra o assassinato de mulheres, em favor do voto universal, do trabalho e da educação feminina. A revista fundada por uma mulher da oligarquia paulista - Virgilina de Souza Salles - e direcionada a outras da mesma classe, dividia o feminismo entre "bom" e o supostamente mal. Ou seja, pregava direitos políticos, contudo a manutenção da mulher primordialmente no ambiente doméstico. Anna Rita Malheiros uma importante colunista do periódico durante os primeiros anos de sua publicação afirmou em sua coluna:

O feminismo pelo qual nos batemos é o que tende a melhorar as condições da mulher brasileira, mantendo-a, porém, a escrava do seu lar, esposa amantíssima, mãe carinhosa, submissa aos seus deveres de honra como mulher e como esposa. (Revista Feminina, 1919, p.5)

Por outro viés as mulheres anarquistas, que também se diziam feministas, ao contrário das burguesas e oligarcas tinham outra proposta de feminismo. Samanta Coalho Mendes diz que:

As mulheres anarquistas (...) começaram a colocar questões que, até então, não eram colocadas pelo anarquismo clássico, como por exemplo, o amor livre, a maternidade livre e consciente, a livre união, o exercício livre do sexo (vale acrescentar que as anarquistas observam o sexo como algo natural e benéfico, ao contrário do que coloca a moral burguesa) e a emancipação da mulher (moral, sexual, política, econômica, intelectual e cultural). (2015, Online)

Apesar dos primeiros nomes que objetivavam alcançar direitos como educação e voto desde os anos 1850, foi somente a partir da fundação da Liga pela Emancipação Intelectual Feminina (1919) e Federação pelo Progresso Feminino (1922) organizadas pela anarquista Maria Lacerda de Moura e pela intelectual Bertha Lutz, que o movimento sufragista ganhou força no cenário nacional. Antônio Ribeiro nos fala que a "a primeira vez que as mulheres conseguiram $O$ direito de votar, os seus votos foram anulados". Este se refere ao caso do Rio Grande do Norte, que havia aprovado Lei Estadual concordando com o sufrágio feminino, porém a Comissão de Poderes do Senado Federal, no ano de 1928, ao analisar essas eleições considerou ilegais por não haver uma lei especial a respeito (RIBEIRO, 2017, Online)

Com a chegada de Getúlio Vargas ao poder, em 1930, ampliou-se ainda mais os espaços de lutas femininas. Em 1931 realizou-se o II Congresso Internacional Feminista sob o comando de Bertha Lutz onde as conquistas do voto ao redor do mundo foram pautas de discussão. Em 1932 Vargas, motivado pelo apoio 
destes grupos, criou-se o Decreto n ${ }^{\circ}$. 21.076, que permitia mulheres votarem, contudo não havia obrigatoriedade do voto feminino. Ribeiro afirma que "Em 3 de maio de 1933 (...) a mulher brasileira pela primeira vez, em âmbito nacional, votaria e seria votada, e caberia a primazia de ser eleita à médica paulista Carlota Pereira de Queiróz, a primeira deputada brasileira" E se ratificou o direito feminino ao voto na Constituição de 1934. Salienta Ribeiro:

Com a promulgação da Constituição de 1934, a idade mínima para o exercício do voto seria alterada para 18 anos, mantida até o advento da Constituição de 1988, que facultou para os maiores de 16 anos o direito ao voto. A legislação eleitoral vigente, garante as mulheres brasileiras a participação efetiva nas eleições, obrigando os partidos políticos apresentarem em suas chapas proporcionais a cota mínima de $30 \%$ de candidatas. (online, 2017).

Assim, com parte das conquistas políticas alcançadas o movimento desarticulou- se dando fim ao que Joana Maria Pedro chamou de "primeira onda feminista". O movimento feminista iria se rearticular e ganhar força novamente em meados dos anos 60 e avançaria em conquistas profundas a partir do final da década seguinte, como veremos a seguir.

Os movimentos sociais formados por mulheres começaram a ressurgir a partir dos anos 1960, especialmente nos Estados Unidos - em meio a luta dos Direitos Civis - e na França em meio as mobilizações de "Maio de 68". Porém somente em 1975, definido pela ONU como o Ano Internacional da Mulher que houve uma formalização das reivindicações femininas de modo mais amplo. Realizou-se no México a "I
Conferência Mundial sobre a Mulher" que teve como resultado a elaboração da Convenção sobre a Eliminação de todas Formas de Discriminação contra as Mulheres considerando múltiplos temas como trabalho, saúde, educação, direitos civis e políticos, estereótipos sexuais, prostituição e família. (BARSTSED, 2001, p.33) No Brasil, a partir do encontro mundial criou-se o Centro da Mulher Brasileira (CMB) e realizou-se em São Paulo o "Encontro para o Diagnóstico da Mulher Paulista" que viria a gerar o Centro de Desenvolvimento da Mulher Brasileira importante responsável na busca de direitos que envolvia o corpo, a sexualidade, a reprodução e o combate à violência, questões que foram implementadas nos anos seguintes. (PEDRO, 2015, Online)

Lia Zanotta Machado fala que "os anos oitenta no Brasil foram caracterizados pelas denúncias feministas sobre a impunidade dos homicídios conjugais" e afirma que foi o momento do “'basta' dado pelas feministas à alegação da defesa da honra como argumento que levava à absolvição ou atenuação do crime” (2010, p.25) Também lembra Machado que neste contexto foram criadas as Delegacias Especializadas em Atendimento à Mulheres (DEAM) que se espalharam pelo Brasil entre os anos 1985 a 1995.

Em Goiás neste período foram criadas diversas organizações feministas sendo elas: Grupo Feminista de Estudo (1981), o Eva de Novo (1981), o Centro de Valorização da Mulher (CEVAM -1981), Núcleo Feminino da Metago (NUFEM - 1982), o Cento Popular da Mulher (COM - 1985), Grupos de Identidade Mulher 
(1985) e o Transas do Corpo (1986).

Cabe destaque o trabalho do CEVAM que se associou a Delegacia Especial de Polícia de Defesa da Mulher em Goiás e a Secretaria Estadual da Condição Feminina para fundar o SOS mulher, que posteriormente se tornaria a Casa Albergue, que recebiam - e recebe até a presente data - as vítimas de violência doméstica e seus filhos, trilhando um caminho pioneiro de cuidado e assistência a mulheres vítimas de violência, ocupando um lugar que posteriormente viria a ser tomado pelo Estado (ABREU, 2001, p.54-56).

As mulheres tomaram o protagonismo das lutas em busca de direitos e ao mesmo tempo foram a campo transformando a realidade de outras iguais. Deste modo a década de oitenta foi muito proveitosa em conquistas e de profundas transformações graças as organizações femininas que com ações e ideias repensaram conceitos e práticas que desencadearam na reformulação do papel feminino, com igualdade e garantias asseguradas na então nova Constituição Federal (1988).

\section{Do Engajamento de Mulheres à Formalização de uma Norma:}

$\mathrm{Na}$ década seguinte, graças aos esforços dos movimentos feministas o Brasil passou a ser signatário de diversas convenções internacionais. Dentre elas a Conferência Mundial sobre os Direitos Humanos de 1993 que foi intitulada Declaração sobre a Eliminação da Violência contra as Mulheres. Esta afirmava que "os direitos da mulher e da menina são parte inalienável, integrante e indivisível dos direitos humanos universais" deste modo qualquer tipo de violência física, psicológica e sexual contra a mulher deveria ser considerada extremamente preocupante. No ano posterior tal declaração ganhou força através da Convenção para Prevenir, Punir ou Erradicar a violência contra Mulher (Convenção de Belém do Pará) assinado pela Organização dos Estados Americanos OEA, sendo esta a fundamentação para criação de uma lei que pudesse criar meios práticos para erradicação da violência contra mulher (BARSTED, 2001, p. 34).

Porém mesmo sendo signatário de acordos que visavam proteger as mulheres, haviam poucas estruturas normativas de proteção a tais até o ano de 2006. Como se sabe o caso que mobilizou o legislativo e do judiciário brasileiro foi a ação promovida pela farmacêutica Maria da Penha Fernandes, que com base na convenção acima mencionada, apoiada por organizações de mulheres buscou em órgãos internacionais auxilio para garantir da sua integridade física e punir seu agressor. Esta sofreu duas tentativas de homicídio pelo seu então companheiro, típico algoz das violações ocorridas em ambiente doméstico. Ao levar a conhecimento às instâncias formais de poder o que de fato lhe aconteceu, Maria da Penha obteve tanto na investigação policial como nos julgamentos a resposta morosa e ineficaz do Judiciário. O que a levou a apresentar uma denúncia contra o Estado Brasileiro na Comissão Interamericana de Direitos Humanos.

A denúncia apresentada por Maria da Penha foi formalizada via Centro de Justiça e pelo Direito Internacional (CEJIL) e pelo Comitê Latino-Americano de Defesa dos Direitos da 
Mulher (CLADEM) e após a devida análise a Comissão Interamericana de Direitos Humanos considerou o seguinte:

Que, com fundamento nos fatos não controvertidos e na análise acima exposta, a República Federativa do Brasil é responsável da violação dos direitos às garantias judiciais e à proteção judicial, assegurados pelos artigos 8 e 25 da Convenção Americana em concordância com a obrigação geral de respeitar e garantir os direitos, prevista no artigo 1(1) do referido instrumento pela dilação injustificada e tramitação negligente deste caso de violência doméstica no Brasil. (...) Que o Estado tomou algumas medidas destinadas a reduzir o alcance da violência doméstica e a tolerância estatal da mesma, embora essas medidas ainda não tenham conseguido reduzir consideravelmente o padrão de tolerância estatal, particularmente em virtude da falta de efetividade da ação policial e judicial no Brasil, com respeito à violência contra a mulher. (...) Que o Estado violou os direitos e o cumprimento de seus deveres segundo o artigo 7 da Convenção de Belém do Pará em prejuízo da Senhora Fernandes, bem como em conexão com os artigos 8 e 25 da Convenção Americana e sua relação com o artigo 1(1) da Convenção, por seus próprios atos omissivos e tolerantes da violação infligida. (Caso n. 12.051 e Relatório 54/01)

A República Federativa do Brasil também recebeu recomendações ao caso particular da Maria da Penha e também acerca dos processos que envolvem violência doméstica. Vejamos:

A Comissão recomenda particularmente o seguinte: Medidas de capacitação e sensibilização dos funcionários judiciais e policiais especializados para que compreendam a importância de não tolerar a violência doméstica; Simplificar os procedimentos judiciais penais a fim de que possa ser reduzido o tempo processual, sem afetar os direitos e garantias de devido processo; $\mathrm{O}$ estabelecimento de formas alternativas às judiciais, rápidas e efetivas de solução de conflitos intrafamiliares, bem como de sensibilização com respeito à sua gravidade e às consequências penais que gera; Multiplicar o número de delegacias policiais especiais para a defesa dos direitos da mulher e dotá-las dos recursos especiais necessários à efetiva tramitação e investigação de todas as denúncias de violência doméstica, bem como prestar apoio ao Ministério Público na preparação de seus informes judiciais. Incluir em seus planos pedagógicos unidades curriculares destinadas à compreensão da importância do respeito à mulher e a seus direitos reconhecidos na Convenção de Belém do Pará, bem como ao manejo dos conflitos intrafamiliares.

A comissão interamericana de Direitos Humanos enviou o relatório n. 54/01 no ano de 2001 e apenas em 2006 foi publicada a Lei n. 11.340. A norma sob enfoque trouxe luz à questão da opressão feminina nas relações domésticas e familiares e provocou debates profícuos sobre a violência clandestina em ambientes intrafamiliares.

Aos oito dias do mês de agosto de 2006 publicou-se a Lei n. 11.340/06, a qual ficou conhecida como Lei Maria da Penha (LMP). A lei, segundo previu o seu artigo 46, entrou em vigor 45 dias depois de sua publicação. A entrada em vigor da norma provocou celebrações em alguns setores sociais, o lançamento de doutrinas jurídicas, as quais fomentaram o estudo do histórico da lei, mostraram avanços, lacunas e críticas, notadamente acerca da atecnia da norma, e provocou ainda, o julgamento da Ação Declaratória de Constitucionalidade (ADC) 19 e Ação Declaratória de Inconstitucionalidade (ADI) 4424 pelo STF. Apesar das controvérsias iniciais, por unanimidade, o Tribunal entendeu pela constitucionalidade da lei, cabendo destaque para fala do Ministro Marco Aurélio: 
para frear a violência doméstica não se revela desproporcional ou ilegítimo o uso do sexo como critério de diferenciação. A mulher é eminentemente vulnerável quando se trata de constrangimentos físicos, morais e psicológicos sofridos em ambiente privado. Não há dúvida sobre o histórico de discriminação e sujeição por ela enfrentado na esfera afetiva. As agressões sofridas são significativamente maiores do que as que acontecem contra homens em situação similar. Além disso, mesmo quando homens, eventualmente, sofrem violência doméstica, a prática não decorre de fatores culturais e sociais e da usual diferença de força física entre gêneros.

Tal fala é emblemática pois acima de tudo é um reconhecimento, no mais ilustre tribunal da nação, da importância de se equilibrar as opressões históricas contra as mulheres. E esta é uma conquista do movimento de mulheres, que escalaram gradativamente o sonho de Gouges.

Michelle Perrot diz que "o corpo está no centro de toda relação de poder. Mas o corpo das mulheres é o centro de maneira imediata e específica" (2005, p.447). A lei sob análise, que este ano completa 10 anos, demonstra a validade dessa assertiva porquanto, conforme se vê da primeira parte deste artigo, é de longa data as opressões e violações experimentadas pelo sexo feminino. Contudo, se observa, com contentamento, que o embate para rechaçar os abusos também resiste há anos. Por óbvio, não se pode falar em solução definitiva para a violência empregada em virtude do gênero, notadamente porque se sabe antecipadamente que a inovação legislativa não tem esse condão (não se pode persistir em soluções mágicas e sedutoras), conforme bem demonstra a linha de ideias do direito penal simbólico, leis recrudescidas, porém, ineficazes na prática, tudo para trazer a falsa segurança à população. É indubitável que a entrada em vigor da lei sob enfoque deu maior visibilidade para as agressões ocorridas em ambientes privados e trouxe ferramentas à disposição das vítimas plasmando um dos fundamentos da Constituição da República, a dignidade da pessoa humana e logo Direitos Humanos.

Segundo Paulo Henrique Gonçalves Portela os Direitos Humanos são aqueles direitos essenciais para que o ser humano seja tratado com a dignidade que lhe é inerente e aos quais fazem jus todos os membros da espécie humana, sem distinção de qualquer espécie (2015, p.26). A comum definição acima retrata o conceito tradicional do tema, contudo, conforme advoga Gregorio Robles (p. 16), a questão conceitual não só não é pacífica, como também é influenciada por pontos de vista de cunho político e ideológico. Para Boaventura de Sousa "na área dos direitos humanos e da dignidade humana" afirma "a mobilização de apoio social para as possibilidade e exigências emancipatórias que eles contem só será concretizável na medida em que tais possibilidades e exigências tiveram sido apropriadas e absorvidas pelo contexto local". (1997, p.23)

Conforme se observou no artigo realizado a quatro mãos, há confluência de pensamento no sentido do exposto pelos dois últimos estudiosos porquanto atender as demandas relativas a Direitos Humanos pressupõe questionar a necessidade de qual indivíduo estamos observando, quais são as suas peculiaridades, características e particularidades, sob pena de 
provocar a falência do discurso de Direitos Humanos pelo simples, pueril e genérico olhar.

Esse pensamento também se aplica ao movimento feminista e suas construções em sede de Direitos Humanos visto que o sujeito feminino tem suas próprias demandas, notadamente pela secular opressão e silenciamento, bem como a imperiosa, para não dizer gritante, necessidade de se fazer escutar, de se fazer respeitar, de preservar seu corpo e sua mente, seus bens imateriais que lhe são caros, afastando os elementos e símbolos de esmagamento do seu ser e do seu ideal de ser mulher.

Pelo empenho de mulheres brasileiras e estrangeiras - que no caso brasileiro se reuniram em prol não só do caso emblemático de Maria da Penha Maia Fernandes, mas também de todas as outras nacionais que sofreram ou estão em condições de vulnerabilidade de violência doméstica - e após acionar organismos internacionais a República Federativa do Brasil publicou a Lei n. 11.340/06, que se tornou, em pouco tempo, ícone no combate a violência de gênero, que é uma conquista fundamental de Direitos Humanos.

\section{Fonte Histórica:}

Revista Feminina, Ano VI. Janeiro à Dezembro de 1919. Disponível no Arquivo Público do Estado de São Paulo. < http://www.arquivoestado.sp.gov.br/>

\section{Bibliografia:}

ABREU, Maria Luiza Gonçalves. Arqueologia do feminismo no Brasil: origem e usos do vocábulo "feminismo" entre as décadas de 18901920 Disponível em <www.memoria.cnpq.br/premios/ig_genero_ 4/mencao_maira_luisa_goncalves.DOC> Consultado em 20/07/2015.

ABREU, Mayra Regina Saraiva de. Cidadania, movimento feminista e feminismo pragmático em Goiás. 2002. Dissertação - Faculdade de Ciências Sociais da Universidade Federal de Goiás. Goiânia, 2002.

BARSTED, Leila Linhares. Lei e realidade social: Igualdade $x$ Desigualdade. In: BARSTED, Leila Linhares; HERMANN, Jacqueline. As mulheres e os Direitos Humanos. Rio de Janeiro: Cepia, 2001.

BRASIL. Constituição Federal. Disponível em $<$ http://www.planalto.gov.br> acesso em 20 de outubro de 2015.

BRASIL. Lei Ordinária n. 11.340 de 07 de agosto de 2006. Disponível em $<$ http://www.planalto.gov.br> acesso em 26 de outubro de 2015.

BRASIL. Supremo Tribunal Federal. Ação Direta de Inconstitucionalidade 4.424 Distrito Federal. Relator Min. Marco Aurélio. 09 de fevereiro de 2012. O Tribunal, por unanimidade e nos termos do voto do Relator, julgou procedente a ação declaratória para declarar a constitucionalidade dos artigos $1^{\circ}, 33$ e 41 da Lei n. 11.340/2006.

BRASIL. Supremo Tribunal Federal. Ação Declaratória de Constitucionalidade 19 Distrito Federal. Relator Min. Marco Aurélio. 09 de fevereiro de 2012. O Tribunal, por maioria e nos termos do voto do Relator, julgou procedente a ação direta para, dando interpretação conforme aos artigos 1, inciso I, e 16, ambos da Lei n. 11.340/06, assentar a natureza incondicionada da ação penal em caso de crime de lesão, pouco importando a extensão desta, praticado contra a mulher no ambiente doméstico, contra o voto do Senhor Ministro Cezar Peluso (Presidente).

\section{COMISSÃO INTERAMERICANA DE DIREITOS HUMANOS. Relatório $\mathrm{n}$.}


54/01.

Disponível

em

$<$ https://www.cidh.oas.org/annualrep/200

Oport/12051.htm $>\quad$ Consultado em

setembro de 2015 .

\section{DECLARAÇÃO DOS DIREITOS DA} MULHER E DA CIDADÃ. Rev. Interthesis, Florianópolis, v. 4, n.1, jan-jun de 2007.

FEBVRE, Lucien. O problema da descrença no século XVI. Lisboa: Editorial Início, 1970.

HUNT, Lynn. A invenção dos Direitos Humanos. Uma história. São Paulo: Cia. Das Letras, 2009.

GOUGES, Olympe. Declaração dos Direitos da Mulher e da Cidadã. Rev. Interthesis, v.4, n.1, Florianópolis. Jan-jun, 2007. Disponível em $<$

https://periodicos.ufsc.br/index.php/inte rthesis/article/viewFile/911/10852>

MACHADO, Lia Zanotta. Feminismo em Movimento. São Paulo: Francis, 2010.

MENDES, Samanda Colhado. Anarquismo $e$ feminismo: as mulheres anarquistas em São Paulo na Primeira República (1889 -1930). Disponível em

http://legacy.unifacef.com.br/novo/public acoes/IIforum/Com\%20EP.html>

Consultado em Agosto de 2015.

SILVA, Alan Tramont; NUNES, Pedro Henrique. Olympe de Gouges: As mulheres e a revolução. Site do Núcleo de Estudos Contemporâneos - Universidade Federal
Fluminense. Consultado em nov. de 2017, disponível em < http://www.historia.uff.br/nec/olympede-gouges-mulheres-e-revolucao>

PEDRO, Joana Maria. Meu corpo minhas regras. Rio de Janeiro: Revista de História da Biblioteca Nacional, Ano 10, n.113, online. Disponível em http://www.revistadehistoria.com.br/seca o/capa/meu-corpo-minhas-regras $>$ Acessado em Agosto de 2015.

PORTELA, Paulo Henrique Gonçalves. Direito Internacional Público e Privado. $7^{\mathrm{a}}$ edição, Editora JusPodivm, 2015.

RIBEIRO, Antonio Sérgio. A Mulher e o voto. Online. Disponível em: $<$ http://www.al.sp.gov.br/alesp/bibliotecadigital/obra/?id=277> Consultado em 21 de Julho de 2015.

ROBLES, Gregorio. Los derechos fundamentales y la ética em La sociedad acutal, p. 16. MALHEIROS, Anna Rita. Revista Feminina, 1919, p.5

SANTOS, Boaventura de Sousa. Por uma concepção multicultural de direitos humanos. Revista Crítica de Ciências Sociais, n.48, jun.1997.

SEVCENKO, Nicolau. Introdução. In: História da vida privada no Brasil, Volume 3. São Paulo: Companhia das Letras, 1998.

SCOTT, Joan.O enigma da igualdade.Rev. Estudos Feministas, Florianópolis, v. 13, janeiroabril de 2005 . 